\title{
Integration of liquid transportation fuel production into airless injection gas-steam cycle
}

\author{
Elizaveta Kalashnikova ${ }^{1,2,}$, Dmitriy Kalashnikov ${ }^{3,4}$, Alexander Pugachuk ${ }^{3,4}$ and Anatoliy Kosoy ${ }^{5}$ \\ ${ }^{1}$ PJSC “ALMAZ R\&P Corp.” LEMZ DIVISION, Dmitrovskoie route 110, Moscow, Russia \\ ${ }^{2}$ Russian State University A.N. Kosygin, Sadovnicheskaia str. 33/1, Moscow, Russia \\ ${ }^{3}$ Joint Institute for High Temperatures, Russian Academy of Sciences, Ijorskaia str. 13/2, Moscow, Russia \\ ${ }^{4}$ Bauman Moscow State Technical University, $2^{\text {nd }}$-Baumanskaia str. 5, Moscow, Russia \\ ${ }^{5}$ Moscow Power Engineering Institute, Krasnokazarmennaia str. 14, Moscow, Russia
}

\begin{abstract}
Mineral fuel combustion negatively impacts on environment. Carbon dioxide (carbonic acid gas) is a danger matter obtained after combustion of such fuel. Deterioration of environment instigates society to invent new effective technologies to minimize anthropogenic emissions. There is an airless injection gassteam cycle [1] for production of electricity and heat energy. Specific character of this cycle is a complete carbon capture. It is realized by liquid oxygen cooling. Also this cycle is characterized by high effectiveness of heat and electrical energy co-production and opportunity of liquid carbon dioxide production, which is convenient for transportation and usage. This diagram provides with reduction of carbon dioxide emissions, while it is impossible in other technologies. Disadvantage of such diagram is impossibility of using captured carbon dioxide in other fields. In this paper perspective method of airless injection gas-steam cycle modernization is offered for further liquefied carbon dioxide conversion into synthesis gas. Eventually, synthetic liquid transportation fuel (methanol) is obtained. Methanol refers to alternative type of fuel. It is an energy intensive, easily used and safe energy carrier. Minimal value of carbon dioxide emissions per produced energy unit of such plant essentially solves problem of anthropogenic influence on environment.
\end{abstract}

\section{Introduction}

In many cases degradation of ecology is connected with anthropogenic emission. Observed climatic changes require immediate solution of this problem. That's why there was a Paris Climate conference in 2015. The aim was to consolidate countries for the fight against global warming and to avoid increasing of a planet average temperature more than $2{ }^{\circ} \mathrm{C}$. Laws related to reducing greenhouse gas emissions are going to be realized to achieve these goals. Firstly, it will affect on industry and energy industry. Nowadays, more than $80 \%$ of global energy consumption is fossil fuel, which gives off carbon dioxide during the combustion (it has been increased 30\% for the last 50-60 years) [2]. It leads to raise of average annual temperature. So, it's necessary to reorganize manufacture industry and energy industry to reduce greenhouse gas emissions [3].

This time, industry has linear system of «stuff- productswaste products», where waste products are get into environment. It is necessary to convert industry into an infinite natural-industrial cycle as «stuff- products- waste products- stuff or products». Also, there are accessory methods for reduction of greenhouse emissions: waste utilization, gas emission treatment and using different types of fuel $[4,5,6]$.

In terms of ecology, today the best decision is consumption change from coal fuel to natural gas. It produces less CO2 (less than $400 \mathrm{~kg} / \mathrm{MW}$ per hour) than coal fuel (about $800 \mathrm{~kg} / \mathrm{MW}$ per hour) [7]. Also, direction of effectiveness increasing related to using fuel for electrical and heat energy production is developing. It should be pointed out that feature of Russian energy industry is combined electrical energy and heat energy production and centralized heat supply from electric power station [8].

Besides mentioned decisions about solving ecological situation, there are such methods as $\mathrm{CO} 2$ recovery from combustion products, which are got after the plant, fuel recovery from carbon before its combustion and fuel

e.chudotvorova@yandex.ru 
combustion in medium of pure oxygen [1]. If complementary cleaning and carbon dioxide liquefaction units are implemented in these technologies, it is possible to get carbon dioxide as a product, which is convenient for transportation. These solutions approach industry to initialindustrial cycle.

\section{Installation diagram, its operating principal and features}

Airless gas-steam cycle can be related to one of the most perspective methods of carbon dioxide capture from combustion products (actuation fluid) [9]. In this cycle pure oxygen is used to acidify fuel. Increasing of all parts of actuation fluid is realized in liquid phase by pumps (that's why the cycle is called «airless»). Pure oxygen from air separating installation is used for condensation of actuation fluid parts. Fuel effectiveness of such cycle is equal to the best modern gas-steam installations. Carbon dioxide capture doesn't make any problems, because discharged actuation fluid consists of carbon dioxide and steam, which condensate at different temperatures.

But problem of further utilization and liquefied carbon dioxide exists. To solve it, airless gas-steam cycle can be modified and process of synthetic liquid fuels (CLF) producing will be involved in it. Liquefied carbon dioxide is a stuff for this cycle. In Figure 1 conceptual diagram of cycle is shown.

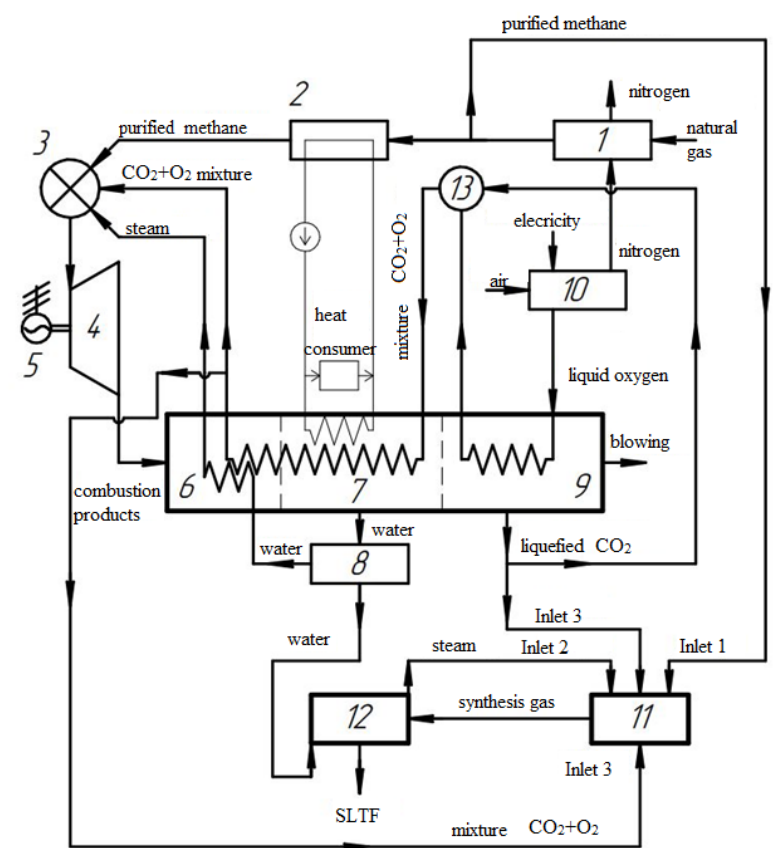

Fig. 1. Conceptual diagram of combined electricity industry and synthetic liquid fuel

1 - liquid methane generator; 2 - methane heater; 3 - combustion chamber; 4 -gas-steam turbine; 5 - electrical generator; 6 exhaust heat boiler; 7 - condenser- delivery water heater; 8 water purifying device; 9 - liquid carbon dioxide generator; $10-$ oxygen unit; 11 - synthesis gas reactor; 12 - methanol converter; 13 - mixing machine.
In this diagram all units and actuation fluid flows are presented. Some of them are secondary elements. Also, heat exchangers are not shown.

Liquid methane generator 1, methane heater 2, combustion chamber 3 , gas-steam turbine 4 , electrical generator 5 , exhaust heat boiler 6 , condenser- delivery water heater 7 , water purifying device 8 , liquid carbon dioxide generator 9 , oxygen unit 10 , synthesis gas reactor 11 , methanol converter 12 , mixing machine 13 are the elements of initial airless cycle, which is described in the article [1]. In this research it is suggested to modify initial diagram by following elements: synthesis gas reactor 1 and methanol converter 12. Description of its operating principle is explained below.

The air comes to oxygen unit 10 as a stuff for producing of liquid oxygen. Obtained oxygen $\left(\mathrm{O}_{2}\right)$ is mixed in mixing machine 13 with liquid carbon dioxide $\left(\mathrm{CO}_{2}\right)$. Then it is heated and one part of this mixture comes to combustion chamber 3, and another one goes to synthesis gas reactor 11. Also, methane $\left(\mathrm{CH}_{4}\right)$, which is purified from sulphur, depleted synthesis gas and steam go to combustion chamber 3. Carbon dioxide and steam, obtained as result after combustion, go to gas-steam turbine 4. Electrical generator 5 is on the one shaft with gas-steam turbine. Inlet pressure before gas turbine is about 3-5 $\mathrm{MPa}$. Then combustion products are delivered into exhaust heat boiler 6 , where they are cooled to water condensation temperature. Then, they are cooled to liquefy carbon dioxide.

Condensated water goes through water purifying device 8 and then to methanol converter 12 . After methanol converter 12 water divides to two flows: one of them is directed to synthesis gas reactor 11 and another one is directed to combustion chamber 3 .

Also condensated carbon dioxide is divided into two parts: the first flow is mixed with oxygen in methanol converter 12 and it is delivered to the combustion chamber 3 and the second one is directed to synthesis gas reactor 11 .

Methane is a fuel in this case. It is purified from sulphur and is directed to synthesis gas reactor 11 and methane heater 2 , where it has got required temperature before the combustion chamber 3 .

In the unit of synthesis gas reactor 11 at pressure of $3 \mathrm{MPa}$ and temperature of $573 \mathrm{~K}$ methane, carbon dioxide and steam are mixed. As a result of chemical reactions of combined conversion $\left(\mathrm{CH}_{4}+\mathrm{CO}_{2}+\mathrm{H}_{2} \mathrm{O}+\mathrm{O}_{2}\right)$ it is possible to obtain synthesis gas without using accessorial energy. In such conversion there are following reactions [9]:

- steam conversion

$\mathrm{CH}_{4}+\mathrm{H}_{2} \mathrm{O} \rightleftarrows \mathrm{CO}+3 \mathrm{H}_{2} \quad \Delta \mathrm{H}=+206 \mathrm{~kJ} / \mathrm{mole}$;

- partial acidification by oxygen

$\mathrm{CH}_{4}+1 / 2 \mathrm{O}_{2} \rightleftarrows \mathrm{CO}+2 \mathrm{H}_{2} \quad \Delta \mathrm{H}=-35,6 \mathrm{~kJ} / \mathrm{mole}$;

- carbon dioxide conversion

$\mathrm{CH}_{4}+\mathrm{CO}_{2} \rightleftarrows 2 \mathrm{CO}+2 \mathrm{H}_{2} \quad \Delta \mathrm{H}=+247 \mathrm{~kJ} / \mathrm{mole}$;

- $\mathrm{CO}$ vapor conversion

$\mathrm{CO}+\mathrm{H}_{2} \mathrm{O} \rightleftarrows \mathrm{CO}_{2}+\mathrm{H}_{2} \quad \Delta \mathrm{H}=-41 \mathrm{~kJ} /$ mole. 
The ratio of synthesis gas components accordingly must be about $1 / 2$ for obtaining methanol.

Obtained synthesis gas is directed to methanol converter 12 for producing synthetic liquid fuel. The reaction of methanol synthesis from synthesis gas is a heterogenic, catalytic, reversible, exothermic reaction. It is described by following equations:

$\mathrm{CO}+2 \mathrm{H}_{2}=\mathrm{CH}_{3} \mathrm{OH} \quad \Delta \mathrm{H}=90,7 \mathrm{~kJ}$,

$\mathrm{CO}+3 \mathrm{H}_{2} \rightarrow \mathrm{CH}_{4}+\mathrm{H}_{2} \mathrm{O} \quad \Delta \mathrm{H}=209 \mathrm{~kJ}(6150 \mathrm{~kJ} / \mathrm{kg})$,

$\mathrm{CO}+2 \mathrm{H}_{2} \rightarrow \mathrm{CH}_{4}+\mathrm{CO}_{2} \quad \Delta \mathrm{H}=252 \mathrm{~kJ}(4200 \mathrm{~kJ} / \mathrm{kg})$,

$\mathrm{CO}+\mathrm{H}_{2} \rightarrow \mathrm{CH}_{2} \mathrm{O} \quad \mathrm{\Delta H}=8,4 \mathrm{~kJ}$,

$\mathrm{CO}_{2}+3 \mathrm{H}_{2} \rightarrow \mathrm{CH}_{3} \mathrm{OH}+\mathrm{H}_{2} \mathrm{O} \quad \Delta \mathrm{H}=49,5 \mathrm{~kJ}$.

Preliminary analyses of thermodynamic equilibrium concentrations of gas components on the outlet side of the reactor are presented in table 1 .

Table 1. Thermodynamic parameters of equilibrium concentrations of gas components

\begin{tabular}{|c|c|c|c|c|c|}
\hline $\begin{array}{l}\text { Position in } \\
\text { the diagram } \\
\text { (look fig. } 1 \text { ) }\end{array}$ & $\begin{array}{c}\text { Inlet } \\
1\end{array}$ & $\begin{array}{c}\text { Inlet } \\
2\end{array}$ & $\begin{array}{c}\text { Inlet } \\
3\end{array}$ & \multicolumn{2}{|c|}{ Outlet } \\
\hline $\begin{array}{l}\text { Pressure P, } \\
\mathrm{MPa}\end{array}$ & 3 & 3 & 3 & 3 & \\
\hline $\begin{array}{l}\text { Temperature } \\
\mathrm{T}, \mathrm{K}\end{array}$ & 573 & 573 & 573 & 1679,4 & \\
\hline Components & \multicolumn{3}{|c|}{ Mass, kg } & Mass, kg & $\begin{array}{l}\text { Concentr } \\
\text { ation, \% }\end{array}$ \\
\hline $\mathrm{O}_{2}$ & 0 & 0 & 74 & 0 & 0 \\
\hline $\mathrm{OH}$ & 0 & 0 & 0 & 0,00011 & 0 \\
\hline $\mathrm{CO}$ & 0 & 0 & 0 & 82,31 & 42,43 \\
\hline $\mathrm{CO}_{2}$ & 0 & 0 & 30 & 32,34 & 16,67 \\
\hline $\mathrm{CH}_{4}$ & 48 & 0 & 0 & 0,004 & 0,002 \\
\hline $\mathrm{N}_{2}$ & 0 & 0 & 4 & 3,99 & 2,06 \\
\hline $\mathrm{H}_{2}$ & 0 & 0 & 0 & 8,87 & 4,57 \\
\hline $\mathrm{H}_{2} \mathrm{O}$ & 0 & 38 & 0 & 66,47 & 34,26 \\
\hline $\mathrm{NH}_{3}$ & 0 & 0 & 0 & 0,006 & 0,003 \\
\hline C (solid) & 0 & 0 & 0 & 0 & 0 \\
\hline $\begin{array}{l}\text { Overall mass, } \\
\mathrm{kg}\end{array}$ & & 194 & & & . \\
\hline
\end{tabular}

Considering mentioned ratio of components in synthesis gas unit production the reaction of combined conversion is realized with heat evolution. As a result there is the synthesis gas $\mathrm{CO}+\mathrm{H}_{2}$ with a ratio of $1 / 1,5$. Thermodynamic analysis parameters of offered diagram depend on choice of catalyst and conditions of synthesis process.

The rest of depleted synthesis gas is directed to the combustion chamber 3 for afterburning.

Presented diagram can be used in practice for creation of mobile power generation unit, which can produce heat and electricity and also liquid transportation fuel, which is used for other energy cycles or it can be commercially realized. This mobile unit can be used for creation of marginal natural gas fields, which is disadvantageously to research by traditional methods. These methods mean monumental construction of gas transmission station. Its cost can be higher than the profit of obtained gas realization. That's why such fields are mothballed and left. Overall gas cost in these marginal fields can be high because there are lots of them. That's why conception of universal mobile unit, which can be transported from one marginal field to another, is commercially advantageous.

Also liquefied carbon dioxide can be used for exploitation of hard-to-recover oil reserves $[10,11]$. To achieve that, liquefied carbon dioxide after mobile unit is converted to gas phase and compressed into the oil field. Due to limited volume of the field, carbon dioxide forces up the oil which goes to the tank for further transportation.

\section{Conclusions}

As a result of modernization of airless cycle it is possible to increase a level of effectiveness for using natural fuel, which is got after producing heat and electrical energy and secondary synthetic liquid fuel. This energy cycle approaches industry field to the industry without waste products. It is an ideal of energy ecology.

Presented technology can be used for energy supply of marginal natural gas fields and it will allow to increase oil recovery of unconventional oil by pumping carbon dioxide in them. Installation which realizes modified airless cycle can be mobile. Then, dependence of field payout on following recovery volume will be dampened, because one such installation can maintain several fields.

\section{References}

1. A. S. Kosoi, Y. A. Zeigarnik, O. S. Popel, [et al.], The Conceptual Process Arrangement of a Steam-Gas Power Plant with Fully Capturing Carbon Dioxide from Combustion Products, Thermal Engineering, no. 9, pp. 597-605 (2008)

2. V. V. Klimenko, A. V. Klimenko, O. V. Mikushina, A. G. Tereshin, To avoid global warming by $2{ }^{\circ} \mathrm{C}$-mission impossible, Teploenergetika, no. 9, pp. 3-8 (2016).

3. V. A. Stennikov, S. V. Zharkov, Method for assessing production efficiency on $\mathrm{CO}_{2}$ emission minimization with emphasis on the energy, Mezhdunarodnyy nauchnyy zhurnal "Al'ternativnaya energetika i ekologiya", no.16-18 (228-230), pp.118-132 (2017).

4. V. M. Maslennikov, Y. A. Vyskubenko, E. A. Tsalko, Methane conversion in a mixture of enriched air and water vapor, High Temperature, vol. 52, no. 5, pp. 654-660 (2014).

5. V. M. Maslennikov, V. Ya. Shterenberg, A highefficiency steam-gas plant for combined electrical power and heat production, High Temperature, vol. 49, no. 5, pp. 750-754 (2011).

6. Braking ground for a groundbreaker: the first Allam Cycle power plant, Modern Power Systems, vol. 36, no.4, pp. 8-10, May (2016). 
7. IEA. Technology roadmap: carbon capture and storage. Report, International Energy Agency (IEA). Paris, 60 p (2013).

8. G. G. Olkhovskyi, A. G. Tumanovskyi, Thermal engineering technology in the period up to 2030, Izvestiya rossiyskoy akademii nauk. Energetika, no. 6, pp. 79-94 (2008).

9. O. V. Krylov, Carbon dioxide conversion of methane to synthesis gas, Rossiyskiy khimicheskiy zhurnal, vol. 44, no 1, pp. 19-33 (2000).

10. A. E. Cherepovitsyn, K. I. Sidorova, I. V. Burenina, Economic evaluation of projects of co 2 injection into oil fields, Elektronnyy nauchnyy zhurnal neftegazovoe delo, no. 5, pp. 337-356 (2014).

11. F. M. Gumerov, Prospects for the use of carbon dioxide to increase oil recovery, Nauchno-tekhnicheskiy sbornik vesti gazovoy nauki, no. 2(7), pp. 93-109 (2011). 